\title{
MEDICINA E MÍDIA: UM ESTUDO SOBRE A FIGURA DO MÉDICO NA TV E NA PERCEPÇÃO DO PÚBLICO
}

\section{MEDICINE AND MEDIA: A STUDY OF THE FIGURE OF THE DOCTOR ON TV AND IN THE PUBLIC PERCEPTION}

\section{MEDICINA Y MEDIOS DE COMUNICACIÓN: UN ESTUDIO DE LA FIGURA DEL MÉDICO EN LA TELEVISIÓN Y LA PERCEPCIÓN PÚBLICA}

\author{
Jeferson Bertolini \\ Pós-doutorando em Jornalismo (UEPG). Doutor em Ciências Humanas (UFSC). \\ Mestre em Jornalismo (UFSC). Bacharel em Comunicação Social/Jornalismo \\ (Univali)

\section{E-mail: jefersonbertolini@gmail.com}

RESUMO: Este artigo destaca pesquisa sobre (a) como a figura do médico é apresentada em programas de televisão sobre saúde e (b) como o público, entendido aqui como conjunto heterogêneo de indivíduos de uma população exposta à mídia de maneira direta ou indireta percebe a figura do médico. O trabalho usa análise de conteúdo do programa Bem Estar, da Rede Globo (81 programas), e observação participante em supermercado e academia de ginástica (78 visitas diárias, em três meses) de Santa Catarina. O estudo analisa a questão sob o prisma do biopoder (FOUCAULT, 2012). Conclui que a televisão, ao dar amplo espaço aos médicos, colabora com o projeto biopolítico da construção de corpos melhorados ou economicamente ativos.

PALAVRAS-CHAVE: Televisão. Médico. Biopoder.

ABSTRACT: This article presents research on (a) how the figure of the physician is presented in health-related television programs and (b) how the public, understood here as a heterogeneous set of individuals of a population exposed to the media directly or indirectly, perceives the figure of the doctor. The work uses content analysis of the program Bem Estar, broadcast by the television network Rede Globo (81 programs) and participant observation in a supermarket and a gymnasium (78 daily visits over three months). The study analyses the issue from the perspective of biopower (FOUCAULT, 2012). It concludes that television, by giving ample space to physicians, collaborates with the biopolitical project of building improved or economically active bodies.

Licença CC BY:

Artigo distribuído sob os termos Creative Commons, permite uso e distribuição irrestrita em qualquer meio desde que $o$ autor credite a fonte original.
KEYWORDS: Television. Doctor. Biopower.

RESUMEN: Este artículo destaca la investigación sobre (a) cómo se presenta la figura del médico en los programas de televisión de salud y (b) cómo el público, entendido aquí 
como un grupo heterogéneo de individuos de una población expuesta directa o indirectamente a los medios, percibe la figura del médico. El trabajo utiliza análisis de contenido del programa Bem Estar de la Rede Globo (81 programas) y observación participante en el supermercado y gimnasio de Santa Catarina (78 visitas diarias, en tres meses). El estudio examina el tema desde la perspectiva del biopoder (FOUCAULT, 2012). Concluye que la televisión, al dar a los médicos un amplio espacio, colabora con el proyecto biopolítico de construir cuerpos mejorados o económicamente activos.

PALABRAS CLAVE: Televisión. Médico. Biopoder.

\section{INTRODUÇÃO}

Este artigo apresenta os resultados de um estudo sobre a participação de médicos em programas de televisão e os possíveis efeitos dessa participação. Buscou-se saber (a) como os médicos são apresentados nesses televisivos e (b) como o público, entendido aqui como um conjunto aleatório de indivíduos expostos a esses programas de maneira direta ou indireta, percebe a figura do médico ${ }^{1}$.

No Brasil, a participação de médicos em programas televisos sobre saúde e bem-estar começou em 2000, quando Drauzio Varella iniciou parceria com o dominical Fantástico, da Rede Globo, apresentando a série Viagem ao corpo humano. A aceitação foi tamanha que, desde fevereiro de 2011 , a emissora mantém um programa diário para tratar do tema, o Bem Estar.

A participação de médicos em programas de televisão sobre saúde deve ser observada com atenção porque, de um lado, há um campo de saber/poder (a medicina) que historicamente reivindica a gestão da vida da população e, de outro, há um veículo midiático capaz de influir sobre as massas (DEFLEUR; BALL-ROKEACH, 1993).

Este trabalho analisa a questão sob a ótica do biopoder, a forma indireta de governar a vida que busca aumentar as potencialidades da população para produzir corpos economicamente ativos (FOUCAULT, 2012). O biopoder se divide em disciplinas (recaem sobre o corpo dos indivíduos, procurando potenciá-los) e biopolítica (recai sobre a população, na tentativa de regulá-la).

Na ótica do biopoder, a medicina está alinhada com a biopolítica há séculos: de início, a medicina se encarregou da proporção de nascimentos, da taxa de reprodução e da fecundidade da população. Tais processos buscavam curar doenças que afligiam a população, que causavam a subtração das forças e a diminuição do tempo de trabalho, além de trazer custos econômicos pela produção não realizada e pelo tratamento feito. Neste contexto, pode-se dizer que a medicina ganhou importância com a proximidade entre política e corpo. "O poder político faz dos corpos o local de seu exercício; à medicina cabe determinar formas e normas pelas quais o corpo politizado será constituído” (FARHI NETO, 2010, p. 32).

$\mathrm{Na}$ perspectiva deste estudo, a televisão potencializa o biopoder porque traduz e faz circular o saber médico, indispensável às técnicas do fazer viver, típicas do biopoder, que vigora no Ocidente desde o século 17.

Este é um estudo interdisciplinar. Associa temas da Filosofia e de outras ciências humanas à Comunicação Social. A interdisciplinaridade "não é um método novo; é uma estratégia eficiente para a compreensão, interpretação e explicação de temas complexos” (MINAYO, 2010, p. 441).

$\overline{1}$ Este trabalho considera que mesmo as camadas da população não expostas à mídia de maneira direta sejam tocadas de maneira indireta por ela, principalmente via amigos, família, líderes comunitários, etc. "Os processos de comunicação sofrem a influência dos meios de comunicação de massa, seja de modo direto, seja em maior escala através dos líderes de opinião" (HABERMAS, 1978, p. 197). 
É “um conceito que invocamos sempre que nos defrontamos com um problema cujo princípio de solução exige o consumo de múltiplas e diferentes perspectivas” (POMBO, 2007, p. 7).

O texto está dividido em seis seções. A primeira detalha a metodologia do estudo. A segunda apresenta os campos da pesquisa. A terceira traz frases extraídas da análise de conteúdo do programa Bem Estar, escolhido por ser o primeiro da televisão brasileira sobre saúde e bem-estar e por ser apresentado diariamente na maior emissora do Brasil. A quinta apresenta frases extraídas de conversas com pessoas durante observação participante (representa o que aqui é chamado de público). A sexta destaca apontamentos bibliográficos sobre o poder medical.

O manuscrito conclui que a televisão, ao dar amplo espaço aos médicos, colabora com o projeto biopolítico da construção de corpos melhorados ou economicamente ativos, e amplia o poder médico no projeto de criar normas corporais.

\section{METODOLOGIA}

Este estudo cruza duas técnicas de pesquisa: análise de conteúdo, para apurar como os médicos são apresentados em programas televisivos; e observação participante em supermercado e academia de ginástica, para apurar como o público percebe a figura do médico (esses estabelecimentos foram escolhidos porque são os lugares em que as pessoas cuidam da alimentação e exercitam o corpo, dois temas ligados à saúde).

A análise de conteúdo foi aplicada ao programa Bem Estar, da Rede Globo. Foram analisados 81 programas (33,19\% dos exibidos em 2016). Escolheu-se o primeiro mês cheio de cada uma das quatro estações do ano.

Este estudo adota o modelo de análise de conteúdo proposto por Bardin (2010). "A análise de conteúdo é um conjunto de instrumentos metodológicos que se aplica a discursos extremamente diversificados. Ela absolve e cauciona o investigador pela atração pelo escondido, o latente, o não aparente" (BARDIN, 2010, p. 7).

A observação participante em supermercado e academia foi feita na Grande Florianópolis. Trata-se da região mais populosa de Santa Catarina, o Estado reconhecido pelos índices de qualidade de vida.

No supermercado, a observação foi feita em visitas diárias, cada uma de 45 minutos, durante 90 dias, em 2016. Elas resultaram em 320 "situações" observadas (situações englobam diálogos entre pesquisador e pesquisado e diálogos entre pesquisados). O procedimento adotado foram conversas com clientes: o autor deste trabalho, no papel de um consumidor comum, conversou com clientes sobre as expectativas deles em relação aos produtos; por que escolheram os itens que estavam na cesta; quais produtos gostariam de levar e não levaram, etc.

$\mathrm{Na}$ academia, a observação também foi feita durante três meses, em 2016. Foram 78 visitas, cada uma com duração entre 45 e 75 minutos. Elas resultaram em 250 "situações" observadas. Matriculado como aluno regular, o autor deste estudo treinou com outros alunos, de diferentes idades e classes sociais, durante o período analisado, procurando saber o que pensam sobre saúde, alimentação, cuidado com o corpo, vaidade, disciplina e afins. As conversas também envolveram instrutores e sócios da academia.

A observação participante é uma técnica etnográfica. Consiste no contato direto do pesquisador com o fenômeno observado, para obter informações sobre a realidade dos atores sociais 
em seu próprio contexto. "Ser testemunha do que as pessoas fazem permite ao pesquisador compreender, em primeira mão, dimensões fundamentais daquilo que lhe interessa da vida social” (RESTREPO, 2010, p. 12).

\section{OBJETO DE ESTUDO: O PROGRAMA BEM ESTAR}

O programa Bem Estar é apresentado de segunda à sexta-feira, ao vivo, entre 10h e 10h45, com o argumento de "ajudar o público a levar uma vida mais saudável”.

O televisivo está na grade de produtos jornalísticos da emissora. É apresentado por dois jornalistas, que adotam a sobriedade do jornalismo ou a informalidade do entretenimento, de acordo com o tema em destaque. Eles contam com a participação de sete médicos consultores (pediatra, psiquiatra, ginecologista, dermatologista, oftalmologista, cardiologista e ortopedista), que participam ao vivo, em sistema de revezamento, de acordo com a pauta.

Além desses sete médicos, o programa escala outros profissionais da saúde, como fisioterapeutas, nutricionistas, farmacêuticos e outros médicos, para fazerem o papel de consultores. Entre titulares e convidados, ao menos dois especialistas participam a cada dia como "especialistas". Todos usam jalecos brancos com nome bordado e se tratam por "doutor". Os não médicos convidados a falar ao vivo, como pesquisadores de alimentos, também adotam o jaleco branco.

O estúdio costuma imitar a sobriedade de um consultório médico, pintado em tom pastel e adornado com livros, maquetes médicas, tubos de ensaio e folhagens discretas. Mas pode reproduzir um ambiente de praia ou de piscina, com espreguiçadeira e guarda-sol, se o tema for ligado ao verão.

O material usado na composição destes ambientes não costuma ser cenográfico. Assim, a mesa da cozinha tem frutas frescas e potes de castanhas, se o assunto exigir; e os consultores e os apresentadores podem se servir. Aliás, é comum vê-los provando algum alimento saudável, como suco de couve ou de um talo qualquer.

O surgimento do Bem Estar se deu após o sucesso de quadros sobre saúde lançados pela Rede Globo em outros programas jornalísticos da emissora. O mais notório deles foi a participação do médico Drauzio Varella no Fantástico.

Em 2018, o Bem Estar atingia, segundo a emissora, 5,8 milhões de telespectadores por dia. A audiência era formada por $68 \%$ de mulheres e $32 \%$ de homens. A maioria era da classe C (47\%). Os demais eram das classes A e D (35\%) e E (18\%). A distribuição do público por faixa etária era: de quatro a $11 \operatorname{anos}(4 \%)$, de 12 a $17(6 \%)$, de 18 a $24(7 \%)$, de 25 a 49 (42\%), maiores de 50 (41\%).

Na tentativa de fazer a mensagem ser assimilada pela audiência, o programa usa três estratégias, que este estudo chama de recursos pedagógicos. Trata-se de recursos metafóricos, recursos didáticos e recursos de signos.

Os recursos metafóricos usam elementos cotidianos, como comida, e se baseiam na comparação. A metáfora facilita a compreensão daquilo que nos rodeia. "A base psicológica da metáfora é o conhecimento de uma coisa em termos de outra” (FEARING, 1978, p. 66).

Os recursos didáticos ajudam a explicar o funcionamento do corpo. Os três mais usados são infográficos, maquetes médicas e comida de verdade. 
Os recursos de signos parecem implícitos. Estão ligados, por exemplo, à vestimenta dos convidados: o jaleco branco é a vestimenta de todos os entrevistados ao vivo. É usado por médicos e por outros especialistas consultados, como biólogos e pesquisadores. Em abordagem clássica, signo é "algo que, para alguém, equivale a alguma coisa, sob um aspecto ou capacidade” (PEIRCE, 1980, p. 10).

\section{ANÁLISE DE CONTEÚDO: O PODER MEDICAL NO BEM ESTAR}

O programa Bem Estar dá amplo espaço aos médicos. Nos 81 programas analisados neste trabalho, foram entrevistados 291 profissionais ligados à saúde. Desse total, 193 (66,32\%) eram médicos, de 35 especialidades. Os 98 restantes (33,67\% do total) eram especialistas em temas afins, como nutricionistas, fisioterapeutas e psicólogos, ou profissionais que, na oportunidade, falavam sobre saúde, como engenheiros de alimentos, químicos e pesquisadores.

Entre os médicos, os cinco especialistas mais entrevistados foram dermatologistas (25 registros), cardiologistas (22), psiquiatras (17), pediatras (14) e endocrinologistas (13). Entre os outros profissionais, os cinco mais ouvidos foram nutricionistas (38 casos), pesquisadores (9), psicólogos (7), biólogos (6) e dentistas (6).

Nas reportagens e nas conversas de estúdio, o público parece conduzido a uma obediência plena à medicina, como se esta fosse detentora dos segredos da vida. Até para espremer cravos é preciso submeter-se ao poder médico. "Esta telespectadora [mulher que enviou foto de cravo no rosto] tem que procurar um dermatologista para se tratar", diz dermatologista ao ver imagem (19/01, sobre cravos e espinhas).

O médico pode aparecer como aquele que sabe o que precisa ser feito e a maneira como deve ser feito: "O exercício deve ser de acordo com o biotipo de cada pessoa. Por isso um bom treinador, associado a um bom médico, é fundamental à prescrição do exercício”, diz médico do esporte (29/01, sobre atividade física); "Indicamos 30 minutos de atividade física por dia, cinco dias por semana. Para a pessoa não correr o risco de excesso é importante ter um profissional orientando”, diz fisiologista (29/01).

Também pode aparecer como aquele que pode evitar o sofrimento alheio ou ajudar aquele que enfrenta algum problema: “Tudo isso tem tratamento. Procure um médico. Não sofra”, diz ginecologista à telespectadora com tensão pré-menstrual (20/04, sobre TPM); "Se ficar triste por mais de duas semanas, a pessoa pode pedir ajuda a um psiquiatra”, diz psiquiatra (08/07, sobre depressão infantil); "Procure ajuda médica", diz psiquiatra a quem quer parar de fumar (04/01, sobre metas de ano novo).

O profissional da medicina conhece as consequências do descuido com a saúde: "O custo de uma doença mental não tratada é muito alto. Não estamos falando de uso indiscriminado de psicotrópicos. Paciente com estado de moderado a grave precisa de medicação", diz psiquiatra (08/07, sobre depressão infantil); "Você tem que procurar um médico porque isto [queda de sobrancelha] pode ser um problema mais grave, que deve ser investigado", diz dermatologista (19/10, sobre queda de cabelo); "Qualquer sangue nas fezes você deve procurar um médico. Pode estar ocorrendo algo mais grave”, diz médico sobre sangramento na evacuação (11/04, sobre prisão de ventre).

Ora o médico aparece como salvador: "A gente [médico] realmente oferece muita qualidade de vida a esses pacientes", diz médica sobre pessoas com tremedeiras (28/04, sobre Parkinson); "Cura é uma coisa para poucos. Mas nós queremos dizer ao planeta que a gente [médico] está tentando chegar lá”, diz otorrino sobre perda de audição (03/10, sobre males do ouvido); “A gente é acusado 
de querer dar remédio de colesterol para todo mundo, de colocar estatina na caixa d'água. O que a gente quer é evitar mortes. Um em cada três brasileiros vai morrer disso. É um caso de saúde pública”, diz cardiologia (26/01, sobre colesterol).

Ora como o único habilitado a falar sobre determinado assunto: "É um nome complicado: distúrbio comportamental do sono REM”, diz médico sobre o sono no Parkinson (28/04, sobre Parkinson); "É a depressão psíquica ressidivante", diz o mesmo profissional sobre outro sintoma da doença.

O efeito desse predomínio médico aparece no próprio programa, entre os doentes entrevistados: "Se você tiver qualquer coisa errada no seu corpo, para e corre no médico para fazer uma investigação", recomenda entrevistada que teve AVC aos 22 anos de idade (13/07, sobre relação entre enxaqueca, infarto e AVC); "Se você pode tratar, se você pode procurar um tratamento, procurar um médico é a melhor coisa a fazer”, diz jovem que sofria com zumbido no ouvido e fez implante (03/10, sobre aparelho de ouvido).

\section{OBSERVAÇÃO PARTICIPANTE: O PODER MEDICAL NA VISÃO DO PÚBLICO}

Aquilo que o médico diz parece ter contornos de autoridade e peso de lei para boa parte das pessoas observadas no supermercado e na academia. Nota-se isso em expressões como "o médico me mandou”, “o médico me proibiu”, “é uma ordem médica”, “o médico brigou comigo” e "ah se teu médico souber disso”.

Nas conversas em que a figura do médico é citada também surgem frases como "gosto de falar com o médico antes", "é sempre bom ir ao médico", "o médico sabe o que diz" e "o médico entende" porque "o médico é uma pessoa estudada”.

Apresentado na televisão como aquele que pode ajudar, salvar, que sabe o que está dizendo e que conhece as consequências do descuido com a saúde, entre o público observado o médico parece firmar-se como autoridade plena, contra a qual ninguém ou poucos se sentem aptos a desconfiar. Assim, o médico tem condições de se apoderar da vida, de regulá-la. Passa a recomendar o momento de engravidar, a forma de fazer sexo, o tipo de repelente a se usar; define aquilo que se coloca no prato, prescreve a atividade física, indica o remédio; sugere aquilo que se deve comprar.

A observação mostra que, quando o médico diz que algo pode ser feito, há uma sensação de segurança por parte do público. Seja em decisões complexas, como interromper um tratamento, ou em escolhas cotidianas, como o que se usa para adoçar o café: "Meu cardiologista diz que eu posso intercalar adoçante com açúcar mascavo", diz mulher diabética e cardíaca que há pelo menos cinco anos, por ordem médica, usa adoçante Stevia. "Eu confio nele [médico]. Acho que o médico estudou para ajudar a gente a viver melhor. Se a gente não confiar no médico, vai confiar em quem?”, pergunta ela, que aparenta 60 anos de idade.

Os exemplos observados indicam que, se o médico diz que determinado produto é saudável, pode-se comprar sem medo: "O médico diz que é bem saudável. Todo mundo lá na academia está usando. Podes usar para fritar. Podes colocar uma colherinha no feijão, que também fica bem bom. Eu estou usando e estou bem contente”, relata mulher sobre o óleo de coco, produto que costuma ser citado como alternativa saudável ao óleo de soja e outros tipos de gordura. "Além de ser gostoso, emagrece. Eu emagreci bastante”, completa ela, que aparenta mais de 60 anos e veste-se com roupas colantes e coloridas. 
Se o médico diz que determinado produto faz bem, deve-se comer o que ele indica, mesmo a contragosto: “Amarga. É ruim mesmo. Mas o médico disse que faz bem pra tudo, então eu não deixo faltar”, diz dona de casa adulta sobre a berinjela; "Nunca gostei de abacate. Mas vi na televisão o médico dizer que o abacate é gordura boa. Puro eu ainda não consigo comer. Mas amasso bem amassadinho, coloco no pão, aí dá para comer”, diz mulher madura que inseriu a fruta na dieta da família recentemente; "É ruim, né? Eu também não gosto. Mas lá em casa a gente só come esse pão [preto] porque minha mulher não pode comer de outro tipo. Foi o médico que mandou”, diz promotor de vendas, espontaneamente, sobre pão integral, ao perceber o autor deste estudo lendo rótulos na prateleira dos pães.

Às vezes, quando o médico manda, abre-se mão de pequenos prazeres do dia a dia, como tomar leite integral no café da manhã: "A médica cortou”, diz mulher, com rosto castigado pelo tempo, sobre leite integral. "Eu botava bem ralinho no café. Uma caixa para mim durava a semana toda. E mesmo assim a médica cortou”, completa ela, que agora toma leite desnatado. A senhora já pensou em levar leite em pó? "Leite em pó também não pode. Tem muito açúcar, muita gordura. Assim me disse a médica. Eu obedeço direitinho”.

Por ordem médica, mostram as observações, há pessoas que eliminam alimentos da dieta de forma permanente, como mostra esta conversa na ilha de alongamento da academia: "Eu não como mais carboidrato", diz mulher madura, que planta ameixa e manga no quintal para lembrar de comer fruta todos os dias. "É difícil, porque a gente estava acostumada e gosta de comer um pãozinho quentinho de manhã, mas carboidrato vira açúcar no sangue. É um perigo”, completa ela. "Eu cortei tudo que é branco. Não como mais pão, macarrão. O pessoal lá de casa tá me acompanhando, mas às vezes reclamam um pouco", responde homem grisalho que se matriculou nas aulas de musculação recentemente, após aposentar-se.

A atividade física prescrita pelo médico deve ser seguida, mesmo que isso imponha sacrifícios: "O médico mandou eu me mexer”, diz jovem cego que, sem dinheiro para continuar na academia e sem espaço em casa para instalar uma esteira elétrica, passou a fazer caminhadas na rua, com ajuda de estranhos. "É meio arriscado. Mas se a gente ficar parado o médico briga", completa ele, ao ser ajudado pelo autor deste trabalho a atravessar a rua; "Eu quase morro. Fico ruim mesmo. Mas tenho que baixar meus exames [índices de gordura]. Por isso me matriculei [na academia]. Eu estou odiando estes ferros. E tem essa música alta, que também é chata. É tudo chato, moço”, diz senhora de meia-idade que faz treino aeróbico e musculação moderada três vezes por semana.

O médico talvez exerça tanta influência porque, entre boa parte dos observados, há uma tendência em enxergar doença em tudo e em todos: “Tu não tens labirintite? É bom cuidar. É coisa séria”, diz homem, apressadamente, ao colega de academia que sentiu pequeno desequilíbrio ao caminhar no chão após 15 minutos na esteira; “Tu não tem diabete?”, pergunta mulher à amiga que, após 45 de treino aeróbico, tomou meia garrafinha de água de uma só vez (sede em excesso é sintoma de diabete); “Tua pressão tá boa?”, pergunta mulher à colega de esteira que dissera "eu gosto de comida com sal" em determinado ponto da conversa (sal em excesso aumenta a pressão); "Eu, no teu lugar, ia procurar um médico", diz homem maduro a colega de treino que se sentiu "um pouco tonto" ao fazer abdominais.

Entre os observados, há quem já tenha percebido que o médico às vezes peca em humildade. "Os médicos não gostam de explicar as coisas. Não sei, parece que eles se sentem ofendidos”, diz mulher madura ao comentar com uma parceira de academia que o enteado de 27 anos faria uma cirurgia na 
bexiga; "Os médicos brigam com a gente", diz dona de casa, cliente de supermercado, que trocou pão branco por torrada integral para regular o peso e não precisar mais ir ao médico; "Tem muita gente que evita procurar um médico por causa disso [da soberba]”, diz cliente de supermercado ao encontrar amigo na gôndola de frutas e ouvi-lo reclamar do palavreado difícil do cardiologista que lhe atendera; "Eu acho que eles [médicos] assustam muito a gente", diz homem maduro ao ver na televisão da academia um médico do Bem Estar reprimindo o consumo da gordura da picanha.

\section{O DOMÍNIO DO PODER MEDICAL}

Não é de hoje, e não é do Bem Estar, que a medicina tem notabilidade. A medicina se converteu em uma das instituições mais importantes da modernidade, embora pareça se interessar mais pela doença do que pelo doente. Ela está no centro de temas contemporâneos, como gestação assistida, transplante de órgãos, manipulação genética, técnicas de reanimação e aparatos de assistência, como próteses. "A medicina quer se situar fora do marco social e cultural ao reivindicar para si a palavra verdadeira, a única científica e, portanto, intocável”. "Tudo acontece como se a medicina fosse a vara com a qual se medisse todas as outras possibilidades de aproximação das doenças" (LE BRETON, 2002, p. 176).

O domínio da medicina é tal que, nos dias de hoje, parece impossível falar do corpo e de seu funcionamento sem recorrer ao vocabulário médico. "Este quadro analítico condiciona a escuta do corpo e nos torna mais atentos aos distúrbios audíveis pelo médico do que aos demais" (FAURE, 2008, p. 13).

Neste cenário, o corpo torna-se alvo de uma medicalização sem precedentes. "Ao assumir atos ordinários da vida, indo além daquilo que fora anteriormente imaginável, a medicina tornou-se não apenas o principal recurso em caso de doença, mas um guia de vida concorrente das tradicionais direções de consciência”. Ela "promulga regras de comportamento, censura os prazeres, aprisiona o cotidiano em uma rede de recomendações”. Sua “justificação reside no progresso de seus conhecimentos sobre o funcionamento do organismo e a vitória sem precedentes que reivindica sobre as enfermidades, atestada pelo aumento regular da longevidade" (MOULIN, 2009, p.15).

A medicalização, encetada em meados do século 19 e apoiada pelos poderes públicos, “fez dos médicos os intermediários obrigatórios da gestão dos corpos presos em uma rede de obrigações em concordância com os grandes acontecimentos da socialização: entrada na escola, serviço militar, viagens, escolha de uma profissão” (MOULIN, 2009, p. 19).

Um dos motivos que explicam por que a medicina expande seus poderes há séculos é o fato de tudo ser convertido em doença. "Da mais remota Antiguidade até o bloco operatório mais futurista, as atitudes em face à doença nada mudaram” (LE GOFF, 1997, p. 7). Isso se deve aos feitos do saber científico, como vacinas, soros e antibióticos.

Se a doença é o mal, e se a medicina luta contra ela, como mostra a análise de conteúdo do Bem Estar, o médico só pode ser visto e aceito como o bem. "Em todas as culturas se aprendeu muito cedo a combater o mal físico com os meios disponíveis: é a medicina empírica”. Ela "é conhecida na Mesopotâmia desde a primeira metade do terceiro milênio, pouco depois do início da escrita” (BOTTERÓ, 1997, p. 11). Para Sournia (1997), a doença não tem existência em si. É uma entidade abstrata à qual o homem dá um nome. Em geral, "a partir das indisposições sentidas por uma pessoa, os médicos criam uma noção intelectual que agrupa os sintomas de que sofre o doente, 
os sinais que um observador pode constatar e as lesões anatômicas". "Estas operações respondem a desejos permanentes do espírito humano, que busca, ante um universo misterioso, nomear, classificar, simplificar, para organizar” (SOURNIA, 1997, p. 359).

A noção de doença tem a ver com uma noção de conhecimento. Daí o destaque aos médicos. Como outros sábios, eles pertencem à sociedade que circunda esse conhecimento. "Sociedade e médicos estão em constante relação de reciprocidade, dispondo os médicos do pretenso poder que se lhes quer conferir e, como se lhes atribui um saber, serão por muitos tempos admirados e invejados, alvos de troça e suspeitos" (SOURNIA, 1997, p. 360).

A medicina colocou a doença no quadro dos paradigmas científicos, enfraquecendo cada vez mais outros saberes, como crenças e tradição. A medicina opôs pesquisa à tradição, observação ao ouvir dizer. A visão da doença muda de acordo com os meios material e social em que se vive: "na Renascença, a melancolia era considerada como um distúrbio admissível na elite em moda; mas se um pobre coitado sofresse de sintomas semelhantes certamente seria censurado de molengão ou descontente" (POTER; VIGARELLO, 2008, p. 441).

Desde Hipócrates (460-377 a.C.) a medicina tenta se afastar das práticas mágicas dos adivinhos e elaborar um modo de agir a partir de um duplo procedimento: procurar as causas das doenças com a ajuda de múltiplas observações e depois aplicar os remédios apropriados. "Esta vontade de aplicar a razão à doença e aos meios de curar”, “de renunciar às práticas mágicas para compreender como e por que as leis que regem o equilíbrio do corpo acabam por ser transgredidas a partir de observações repetidas, está na origem na medicina moderna” (MOSSÉ, 1997, p. 41).

\section{CONCLUSÃO}

Na televisão, como mostra o exemplo do programa Bem Estar, o médico aparece como um salvador, um sujeito superior, como aquele que pode ajudar e como o único habilitado a falar sobre o corpo e o bom funcionamento dele.

Na análise de conteúdo do programa, o tema médico aparece 123 vezes na amostra analisada, de 81 programas. Significa que, 1,5 vez por programa, o Bem Estar levou ao público frases que apresentam o médico como figura que detém conhecimentos salvadores e que por isso deve ser seguido, admirado e obedecido.

Entrevistar médicos é elementar em um programa de televisão sobre saúde e bem-estar. O que esta pesquisa aborda é o espaço televisivo dado aos médicos, a valorização do que dizem e a aceitação aparentemente passiva ao que dizem. Em síntese, os médicos entrevistados sustentam a noção de que detêm a verdade sobre a saúde da população, o que lhes confere poder sobre os demais.

Entre os observados em campo, o médico também é visto como um salvador e como aquele que pode curar. Este resultado é compatível com os estudos iniciados em 1920 por Lasswell (1938). Esses estudos mostram que a mídia exerce alguma influência sobre o público. No caso desta pesquisa, significa que a mídia influi na percepção do público sobre a figura do médico.

Do ponto de vista do biopoder, com o qual este estudo está alinhado, um dos efeitos da abrangência da ação medical é o estabelecimento de normas: o sistema medical, com todo o aparato que lhe serve de apoio, passa a estipular normas e a aplicá-las aos indivíduos. "A sociedade passa a se regular, a se ordenar, a se condicionar, de acordo com as normas físicas e mentais que são 
determinadas por processos medicais" (FARHI NETO, 2010, p. 30). Neste contexto, este estudo conclui que, ao dar visibilidade ao médico, ampliando as oportunidades desse profissional de intervir na vida da população, a televisão colabora com o projeto biopolítico da construção de corpos melhorados ou economicamente ativos.

\section{REFERÊNCIAS BIBLIOGRÁFICAS}

BARDIN, Laurence. Análise de conteúdo. Lisboa: Edições 70, 2010

BOTTERÓ, Jean. A magia e a medicina reinam na Babilônia. In: LE GOFF, Jacques (et al). As doenças têm história; tradução de Laurinda Bom. Lisboa: Terramar, 1997

DEFLEUR, Melvin. BALL-ROKEACH, Sandra. Teorias da Comunicação de massa; tradução de Otávio Alves Velho. Rio de Janeiro: Jorge Zahar Editor, 1993

FARHI NETO, Leon. Biopolíticas: as formulações de Foucault. Florianópolis: Cidade Futura, 2010

FAURE, Olivier. O olhar dos médicos. In: CORBIN, Alain; COURTINE, Jean-Jacques; VIGARELLO, Georges. História do corpo: da revolução à grande guerra; tradução de João Batista Kreuch e Jaime Clasen. Petrópolis: Vozes, 2008

FEARING, Franklin. A comunicação humana. In: COHN, Gabriel. Comunicação e indústria cultural. 4. ed. São Paulo: Cia Editora Nacional, 1978

FOUCAULT, Michel. História da sexualidade I: a vontade de saber; tradução de Maria Thereza da Costa e J. A. Guilhon Albuquerque. Rio de Janeiro: Graal, 2012

HABERMAS, Jüngen. Comunicação, opinião pública e poder. In: COHN, Gabriel. Comunicação e indústria cultural. 4. ed. São Paulo: Cia Editora Nacional, 1978

LASSWELL, Harold. Propaganda technique in the word war. Nova York: Peter Smith, 1938

LE BRETON, David. Antropologia do corpo e modernidade. Buenos Aires: Nueva Visión, 2002

LE GOFF, Jacques (et al). As doenças têm história; tradução de Laurinda Bom. Lisboa: Terramar, 1997

MINAYO, Maria Cecília de Souza. Disciplinaridade, Interdisciplinaridade e Complexidade. In: Revista Emancipação. Ponta Grossa, 2010

MOSSÉ, Claude. As lições de Hipócrates. In: LE GOFF, Jacques (et al). As doenças têm história. 2. ed. tradução de Laurinda Bom. Lisboa: Terramar, 1997

MOULIN, Anne Marie. O corpo diante da medicina. In: CORBIN, Alain; COURTINE, Jean-Jacques; VIGARELLO, Georges. História do corpo: as mutações do olhar; o século XX; tradução de Ephraim Ferreira Alves; 3. ed. Petrópolis: Vozes, 2009

PEIRCE, Charles Sanders. Escritos coligidos; tradução de Armando Mora D’Oliveira e Sérgio Pomerangblum; 2. ed. São Paulo: Abril Cultural, 1980

POMBO, Olga. Epistemologia da Interdisciplinaridade. Conferencia proferida no Colóquio Interdisciplinaridade, Humanismo e Universidade, promovida pela Cátedra Humanismo Latino. Porto, 2007

POTER, Roy; VIGARELLO, Georges. Corpo, saúde e doenças. In: CORBIN, Alain; COURTINE, JeanJacques; VIGARELLO, Georges. História do corpo: do Renascimento às luzes. Petrópolis: Vozes, 2008

RESTREPO, Eduardo. Técnicas etnográficas. In: Especialización en Métodos y Técnicas de Investigación en Ciencias Sociales. Fucla, 2010

SOURNIA, Jean-Charles. O homem e a doença. In: LE GOFF, Jacques (et al). As doenças têm história. 2. ed. Tradução de Laurinda Bom. Lisboa: Terramar, 1997 